\title{
Correlation Between Salivary and Blood Nickel Concentration in Smokers and Nonsmokers
}

\author{
Daniel, Filipe Ivan*1, Feller, Georgia Voltolini², Krieger, Heloisa Aparecida de Carvalho ${ }^{2}$, Grando ${ }^{1}$, Liliane \\ Janete $^{1}$,Dos Santos, Claudia Regina ${ }^{1}$ \\ ${ }^{1}$ Department of Pathology, Health Science Center, Federal University of Santa Catarina, Brazil \\ ${ }^{2}$ Dentistry Graduate Program, Health Science Center, Federal University of Santa Catarina, Brazil

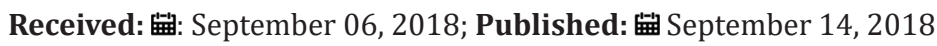 \\ *Corresponding author: Filipe Ivan Daniel. Departamento de Patologia, Centro de Ciências da Saúde, Universidade Federal de Santa \\ Catarina. Rua Delfino Conti, s/n CEP. 88040-370, Florianópolis, SC, Brasil
}

\begin{abstract}
Nickel is a naturally occurring heavy metal in the environment, and one of the harmful compounds found in tobacco, as it accumulates in the plant Nicotina tabacum. It is also considered a carcinogen in humans. Its concentrations in the body can undergo many variations and its determination in body fluids can be an important way to monitor exposure to this carcinogen. This paper aimed to analyze salivary and blood nickel concentrations in smokers and nonsmokers. Salivary/blood concentrations of 23 individuals were determined by graphite furnace atomic absorption spectroscopy. We found higher nickel salivary concentration in non-smokers ( $8.28 \mu \mathrm{g} . \mathrm{L}^{-1}$ versus $\left.4.23 \mu \mathrm{g} . \mathrm{L}^{-1}\right)$, While blood concentration was greater in smokers $\left(2.22 \mu \mathrm{g} . \mathrm{L}^{-1}\right.$ versus $\left.1.02 \mu \mathrm{g} . \mathrm{L}^{-1}\right)(\mathrm{p}<0.05$, Wilcoxon signed-rank test).Salivary concentration was 3.5 times higher in saliva than in blood, with no statistical correlation between the samples. Although saliva is considered a good biological matrix, easy to collect/store, allowing the detection of nickel with the same technique already used for blood, it was not a suitable substrate for estimating the concentration of nickel in the blood. In addition, unexpectedly, greater amounts of nickel were found in the saliva of nonsmoking individuals possibly resulting from nickel sources other than smoking.
\end{abstract}

Keywords: Nickel; Tobacco; Saliva; Cancer

Abbreviation: Ni: Nickel; As: Arsenic; Cd: Cadmium; Cr: Chromium; UFSC: University Hospital of Federal University of Santa Catarina; LOD: The limit of detection; LOQ: The Limit of Quantitation; RSD: Relative Standard Deviation

\section{Introduction}

Nickel (Ni) is a metal element found throughout the soil, with wide use in processes such as mining, smelting, metal manufacturing residues, ash and sewage sludge. Humans are exposed to nickel through air, food and water, occupational exposure and some habits such as smoking [1]. The tobacco plant has a natural ability to accumulate large amounts of minerals from the contaminated soil, thus it serves as a source of nickel and other metals to the human body [2]. In addition, cigarette smoking is the main etiological factor for many cancers such as lung, bladder, and mouth [3]. As the habit of smoking often persists for several years, smoking can be a great source of nickel for humans, tending to increase its levels in the body [2]. Nickel compounds are classified according to IARC (International Agency for Research on Cancer) as agents 1 , known to be carcinogenic to humans similarly to other metals such as arsenic (As), cadmium (Cd), and chromium (Cr) [4]. The association between exposure to some metals, smoking, and cancer is dose dependent, with oncogenic risk proportional to the number of cigarettes smoked per day and smoking habit duration $[5,6]$.

In addition, the amount of nickel and other constituents in cigarettes varies according to origin and brand. Studies evaluating this parameter showed level of $1.26 \pm 0.449$ ug.g- 1 of tabaco in Brazil [2], 1.1 to 3.9 ug.g-1 in North American [7], and 0.79 ug.g-1 in Chine [8]. The amount of nickel absorbed by the body depends on how much is inhaled, ingested, or in contact with the skin, apart from its physical and chemical characteristics, and the solubility of nickel, an important factor for all absorption pathways. Generally, its absorption is higher for nickel carbonyl, followed by soluble compounds, nickel metal, and its insoluble compounds. Once absorbed, it reaches the bloodstream, binds to protein carriers and affects all organs and tissues [1]. Its blood concentrations may undergo many variations. According to Stojanovic et al. [9], blood and urine concentration increases in smokers, but factors such as the intensity of elimination and concentration in organs may also influence.

Thus, for levels determination and concentration comparisons, some factors must be taken into consideration such as: the individual geographic origin, diet, smoking habits, the ability to eliminate it, and the analytical method used for analysis. Concentration determination of nickel and other metals in biological fluids can be an important way of monitoring exposure to these carcinogens 
agents and predicting or estimating the risk of cancer development. Accordingly, blood and urine are the most adequate biological fluids for this biomonitoring $[10,11]$. However, it can also be found in hair, sweat and saliva [12-14]. According to Olmedo et al. [15] saliva analysis is complementary to that of classic body fluids, such as blood and urine, since nickel salivar concentration may reflect the concentration in other fluids, especially blood. Thus, the aim of this study was to conduct an analysis of nickel concentrations in saliva of smokers and nonsmokers, seeking to evaluate possible correlations with blood values through graphite furnace atomic absorption spectroscopy.

\section{Materials and methods \\ Population Studied}

The sample consisted of patients from the Clinic of Stomatology of the University Hospital of Federal University of Santa Catarina (UFSC), with neoplastic and non-neoplastic oral lesions, from November 2013 to July 2014. The study was approved by the Committee of Ethics in Research with Humans of UFSC (approval under number 467.387) and all the participants signed the informed consent form. Patients with evidence of exposure to metals from sources other than cigarettes were excluded from the sample. Data obtained were previous medical history, medication use, smoking habits, and alcoholism.

\section{Collection and Storage of Blood and Saliva Samples}

Blood collection occurred at Clinical Laboratory of University Hospital of UFSC by obtaining $4 \mathrm{~mL}$ of peripheral blood that were stored in tubes with EDTA at $4^{\circ} \mathrm{C}$ until analysis. Total saliva was collected following the standards used by Koseki et al. [16] and the methodology of Navazesh $[17,18]$ immediately after blood collection. Activities such as brushing teeth, eating, smoking, ingesting liquids, applying cosmetics or drugs to the lips for 1 hour prior to collection were suspended. During the procedure, patients were kept seated and with eyes open, with a duration of up to 5 minutes or obtaining a minimum of $1 \mathrm{~mL}$ of the substrate. Thereafter, the saliva was stored at $-20^{\circ} \mathrm{C}$ until analysis.

\section{Preparation and analysis of blood and saliva samples}

Blood and saliva analyze were performed at Toxicological Research Laboratory of UFSC, using graphite furnace atomic absorption spectroscopy (Thermo Scientific, Ice3000, UK), following the proposed by Olmedo et al. [15]. After being homogenized at room temperature, the $500 \mu \mathrm{L}$ of blood were diluted in the ratio $1: 4$ by nitric acid solution $0.2 \%$ and $0.1 \%$ Triton $\mathrm{X}-100$. The saliva samples were thawed at room temperature and centrifuged at $282 \mathrm{~g}$ for 5 minutes at $25^{\circ} \mathrm{C}$. From the supernatant $500 \mu \mathrm{L}$ were diluted in $1: 2$ rate, in $0.2 \%$ nitric acid solution, and $0.1 \%$ Triton X-100. Calibration curves were prepared with different concentrations of nickel $\left(5,10,15\right.$ and $20 \mu \mathrm{g}$. $\left.\mathrm{L}^{-1}\right)$ directly into blood and saliva samples. For the preparation of the calibration points and the samples, they were diluted with $0.2 \%$ nitric acid and $0.1 \%$ Triton X-100. Ammonium dihydrogen phosphate 10 g.L.-1 was used as matrix modifier. All reagents used were Merck®, Darmstadt, Germany.

The method was optimized according to the programming of temperatures that included the best conditions for pyrolysis and atomization. These temperatures were: $110^{\circ} \mathrm{C}$ (drying), $130^{\circ} \mathrm{C}$ (drying), $900^{\circ} \mathrm{C}$ (pyrolysis), $2.300^{\circ} \mathrm{C}$ (atomization) and $2,500^{\circ} \mathrm{C}$ (cleaning the graphite furnace). After the optimization, the method was duly validated. The method was linear for the working range proposed in both matrices. The limit of detection (LOD) was 0.580 and $0.507 \mu \mathrm{g} . \mathrm{L}^{-1}$ for saliva and blood respectively, while the limit of quantitation (LOQ) was 1.960 and $1.690 \mu \mathrm{g} . \mathrm{L}^{-1}$ for saliva and blood respectively. For all concentrations under study, the Relative Standard Deviation (RSD) was less than $10 \%$ for both evaluations, intra and inter day accuracy.

\section{Statistical Analysis}

Nickel concentrations in blood and saliva were compared using the Wilcoxon paired-test. The correlation between metal concentrations in the blood and saliva samples was determined by Spearman's Correlation Test. All data were analyzed in Action 2.7 software, in which a value of $\mathrm{p}<0.05$ was considered statistically significant.

\section{Results}

A total of 23 individuals, smokers and nonsmokers, were included in the study. The age-related information, gender, comorbidities, medication use and alcohol consumption are shown in Table 1. As some patients needed to collect blood to perform routine tests requiring fasting, $43 \%$ of samples of blood and saliva were collected in the morning (Table 1). Nickel blood and saliva concentrations reported in Table 2 (range of $0.84-6.66$ $\mu \mathrm{g} . \mathrm{L}^{-1}$ and $0.98-24.21 \mu \mathrm{g} . \mathrm{L}^{-1}$, respectively) were consistent with other studies $(9,18,19)$. Results showed a higher concentration of saliva nickel in nonsmokers, while the blood concentration was higher in smokers, with no statistical difference between the two groups evaluated for both samples, as shown in Table 2 and Figure 1. When comparing all individuals, regardless of smoking habits, saliva concentration was 3.5 times higher than blood level $(\mathrm{p}<0.05$, Table 2 and Figure 2), although there was no statistical correlation between these samples ( $p>0.05$, Spearman's coefficient). It was not possible to establish a correlation with the average number of smoked cigarettes under the following conditions: on the collection day (3.3 cigarettes), on the previous day (10 cigarettes) with daily consumption (18:23 cigarettes), or time of smoking (28 years) ( $p>$ 0.05 , Spearman coefficient).

Table 1: Characteristics of study subjects.

\begin{tabular}{|c|c|c|c|}
\hline & Smokers & Non-smokers & Total \\
\hline \multicolumn{4}{|c|}{ Sex } \\
\hline Male & $5(38.5 \%)$ & $1(10 \%)$ & $6(26.1 \%)$ \\
\hline Female & 8 (61.5\%) & $9(90 \%)$ & 17 (73.9\%) \\
\hline \multicolumn{4}{|c|}{ Age (years) } \\
\hline Mean \pm SD & $49.92 \pm 9.01$ & $55.7 \pm 8.28$ & $52.43 \pm 8.99$ \\
\hline Range & $39-66$ & $45-69$ & $39-69$ \\
\hline \multicolumn{4}{|l|}{ Comorbidities } \\
\hline Hypertension & $4(30.8 \%)$ & $3(30 \%)$ & $7(30.4 \%)$ \\
\hline Diabetes & $3(23.1 \%)$ & $2(20 \%)$ & $5(21.7 \%)$ \\
\hline Medication & & & \\
\hline
\end{tabular}




\begin{tabular}{|c|c|c|c|}
\hline Antidepressant & $3(23.1 \%)$ & $2(20 \%)$ & $5(21.7 \%)$ \\
\hline Antihypertensive & $3(23.1 \%)$ & $4(40 \%)$ & $7(30.4 \%)$ \\
\hline Diabetes medication & $3(23.1 \%)$ & $2(20 \%)$ & $5(21.7 \%)$ \\
\hline Etilism & & & \\
\hline Yes & $1(7.7 \%)$ & $0(0 \%)$ & $1(4.3 \%)$ \\
\hline No & $12(92.3 \%)$ & $10(100 \%)$ & $22(95.7 \%)$ \\
\hline Collection time & & & \\
\hline Morning & $5(38.5 \%)$ & $5(50 \%)$ & $10(43.5 \%)$ \\
\hline Late afternoon & $8(61.5 \%)$ & $5(50 \%)$ & $13(56.5 \%)$ \\
\hline Total & $13(56.52 \%)$ & $10(43.48 \%)$ & $23(100 \%)$ \\
\hline
\end{tabular}

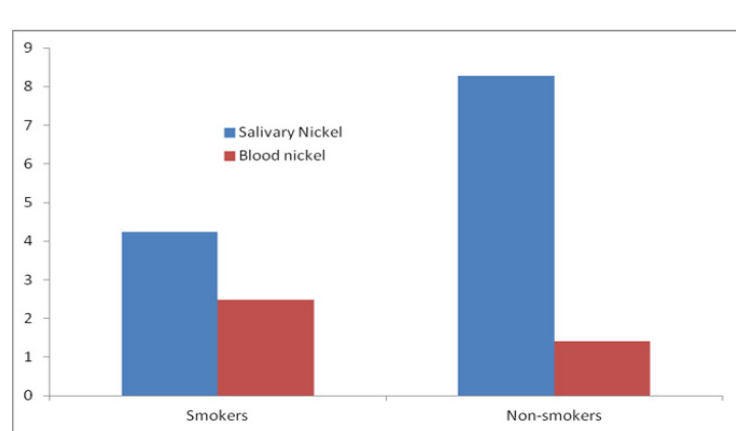

Figure 1: Means of salivary and blood nickel concentration $\left(\mu \mathrm{g} . \mathrm{L}^{-1}\right)$ in smokers and non-smokers.

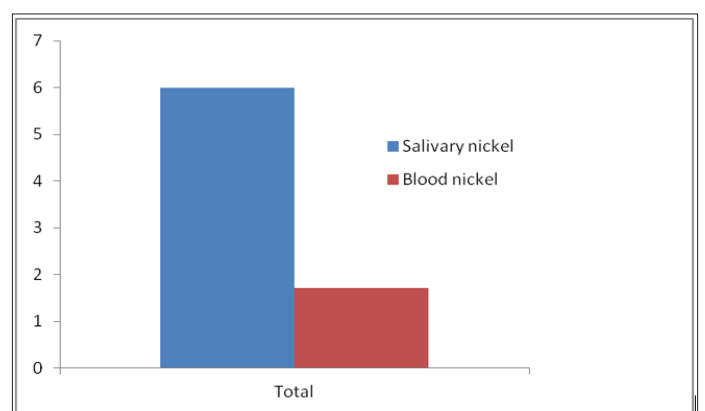

Figure 2: Means of salivary and blood nickel concentration $\left(\mu \mathrm{g} . \mathrm{L}^{-1}\right)$ in total sample.

\section{Discussion}

Chronic exposure to metals has been recognized as an increasing factor for the incidence of cancer in exposed individuals [1219-22], so that the biomonitoring of these carcinogens in our bodies becomes increasingly important. Except for occupational exposure, smoking can be an important source of exposure to heavy metals and may partly explain their high variability in blood samples [23]. Thus, this study aimed to determine and assess possible correlations between nickel blood and salivary concentrations in simultaneously collected samples from the same participants, enabling to evaluate how smoking habits can affect such concentrations.

Table 2: Salivary and blood nickel concentrations.

\begin{tabular}{|c|c|c|c|c|c|c|c|c|}
\hline \multirow[b]{2}{*}{ Sample } & \multirow[b]{2}{*}{ Female } & \multirow[b]{2}{*}{ Male } & \multirow[b]{2}{*}{ Smokers } & \multirow{2}{*}{$\begin{array}{l}\text { Non- } \\
\text { smokers }\end{array}$} & \multirow[b]{2}{*}{ Total } & \multicolumn{2}{|c|}{$\begin{array}{l}\text { Wilcoxon signed-rank test p } \\
\text { value for }\end{array}$} & \multirow{2}{*}{$\begin{array}{c}\text { Spearman } \\
\text { coefficientSaliva X } \\
\text { Blood }^{*}\end{array}$} \\
\hline & & & & & & $\begin{array}{l}\text { Smokers } \\
\text { X Non- } \\
\text { smokers }\end{array}$ & $\begin{array}{c}\text { Saliva X } \\
\text { Blood* }\end{array}$ & \\
\hline $\begin{array}{c}\text { Saliva }\left(\mu \mathrm{g} . \mathrm{L}^{-1}\right) \\
\text { Mean } \pm \mathrm{SD}\end{array}$ & $6.63 \pm 5.48$ & $4.19 \pm 1.80$ & $4.23 \pm 1.66$ & $\begin{array}{c}8.28 \pm \\
6.64\end{array}$ & $\begin{array}{c}5.99 \pm \\
4.87\end{array}$ & & \multirow{3}{*}{0.0003} & \multirow{3}{*}{$\begin{array}{l}r=-0.253 \\
p=0.405\end{array}$} \\
\hline Range & $0.98-24.21$ & $3.12-7.81$ & $2.35-7.98$ & $0.98-24.21$ & $0.98-24.21$ & 0.047 & & \\
\hline $\begin{array}{c}\text { Blood }\left(\mu \mathrm{g} \cdot \mathrm{L}^{-1}\right) \\
\text { Mean } \pm \mathrm{SD} \\
\text { Range }\end{array}$ & $\begin{array}{l}1.48 \pm 0.95 \\
0.84-4.27\end{array}$ & $\begin{array}{l}2.34 \pm 2.29 \\
0.84 \pm 4.27\end{array}$ & $\begin{array}{c}2.22 \pm 1.69 \\
0.84-6.66\end{array}$ & $\begin{array}{c}1.02 \pm \\
0.39 \\
0.84-1.85\end{array}$ & $\begin{array}{c}1.70 \pm \\
1.41 \\
0.84-6.66\end{array}$ & 0.021 & & \\
\hline
\end{tabular}

According to Khlifi et al. [23], no significant differences in nickel blood concentrations have been found for men and women, although Gil et al. [24] have found higher blood and saliva levels in women. In this study, concentrations were lower in the blood and higher in the saliva of women. However, it is important to point out that our sample consisted of approximately $74 \%$ of female patients, which can hamper inferences related to gender. Despite the advantages of using saliva for analysis in this study no correlation was found between concentrations of nickel in blood and saliva, i.e., saliva was not a suitable substrate for its prediction in the blood.

Metal ions are not passively diffused to the saliva glands, but actively transported, which may explain the lack of correlation between saliva and blood [24]. In addition, some considerations about the results described herein. Nickel concentrations found in the saliva were higher than those found in blood (means of 5.99 $\mu \mathrm{g} . \mathrm{L}^{-1}$ and $1.70 \mu \mathrm{g} . \mathrm{L}^{-1}$, respectively). By individually observing each participant, we have noted that only 3 showed less than or equal salivary concentrations compared to blood (data not shown). Thus, in most samples, participants had highest nickel values in saliva than in blood. Similar results have been found by Gil et al. [24], in which nickel levels in saliva were 14 times higher than in blood.

It is possible to consider that salivary mechanisms play an important role in excreting nickel from the body; in other words, saliva can be a substrate for nickel excretion to prevent high concentrations in the blood, acting synergistically to urinary excretion, although the analysis on this biological matrix is out of our scope. A second and more probably hypothesis is that other source of nickel in contact with the oral cavity may cause such elevation without elevating blood concentration. The presence of removable partial dentures, nuclei, orthodontic appliances, metal 
ceramics [25-28] and even oral piercings [29] may justify a higher concentration of salivary nickel, since this is one of the ten most commonly found metals in dental alloys used in the manufacture of these devices [26-28]. Moreover, nickel has a greater tendency to be released from alloys compared to noble metals, since it has low resistance to corrosion and, therefore, is released to the saliva when present in the buccal cavity $[26,30]$. Unfortunately, no information about these devices were collected from our sample, due to its difficulty of quantifying their existence.

Therefore, it was not possible to establish this correlation, although no patient had any orthodontic appliance. Other variables that affect saliva, such as diet, medications use that interfere with salivary flow, smoking, occupational exposure and the period of the day of collection may also influence the concentration. As smoking patients were at least 1 hour without smoking prior to sample collection, the possibility that nickel present in saliva were from direct contact with cigarette smoke was minimized. When comparing the results in relation to the habit of smoking, we found a higher mean salivary concentration in non-smokers than in smokers. Some hypotheses may be raised to explain this unexpected result. The first one is the fact that three samples from the non-smoker group had very high concentrations (11.57 $\mu \mathrm{g} . \mathrm{L}^{-1}, 12.79 \mu \mathrm{g} . \mathrm{L}^{-1}$, and $24.21 \mu \mathrm{g} . \mathrm{L}^{-1}$ ), contributing to the mean concentration increase.

If we considered that these individuals presented another unknown source of nickel and thus excluding such samples from this group the mean of the non-smoker group would be very like the smoking group, with no statistical difference ( $4.88 \mu \mathrm{g} . \mathrm{L}^{-1}$ versus $4.23 \mu \mathrm{g} . \mathrm{L}^{-1}$, respectively, $\mathrm{p}=0.3$, Wilcoxon signed-rank test). So that the presence of smoking may not be an important factor for salivary elevation of the nickel, corroborating with another study by Catalanatto and Sunderman that found no significant difference between the concentrations of nickel in saliva from smokers and non-smokers patients [31]. The difficulty of producing saliva during the collection of some of the participants may also have interfered in the concentrations of nickel. Many drugs used may cause hypo salivation, such as opioids, antihistamines, antidepressants, antiepileptic's, anxiolytics and anticholinergics [32,33]. Of the total number of participants, only 5 used antidepressants. Another factor that can also lead to low saliva production is the anxiety experienced by patients at the collection time. It is noteworthy that in this study we could not evaluate the behavior of nickel in situations of hypo salivation and compare it with a normal salivary flow. Regarding the blood analysis, the mean of nickel was significantly higher in smokers, proving that analysis in the blood may be a good marker of heavy metal from smoke exposure. In this way, the blood proved to be a good biological matrix for nickel monitoring, with potential usefulness for predicting the risk of diseases related to this exposure such as cancer.

Classically, blood and urine concentrations are considered representative of recent metal exposure, in contrast to other samples such as hair, which predict past exposure [23,25]. Because it is a biological matrix in constant production and elimination, it is assumed that saliva is also capable of demonstrating recent exposure to metals. Although it is not well known the nickel toxicokinetic in saliva, it may still be influenced by local factors such as those already explained above. Several investigations associated the presence of heavy metals in the body with smoking, as well as its possible synergistic effect with other risk factors for diseases such as systemic arterial hypertension [34]. In this study, due to the small number of patients presenting comorbidities, it was not possible to correlate nickel concentrations with systemic arterial hypertension or diabetes, as well as with the use of antihypertensive drugs, hypoglycemic agents or with the use of antidepressants.

\section{Conclusion}

Although this research presents limitations, it was possible to evaluate the behavior of nickel concentrations in the blood sample, as determined by the literature as a good biological material to nickel dosage. Although saliva did not show direct correlation with the nickel circulating concentrations, it's important to highlight that it is a biological matrix of easy collection and storage, that allowed nickel detection under the same technique used to the other matrices. Further study should be conducted on the possibility of using it in the monitoring of nickel exposure.

\section{Acknowledgment}

We would like to thank all the staff of the Clinical Laboratory of University Hospital of Federal University of Santa Catarina for enabling sample collection with safety.

\section{Funding}

This research did not receive any specific grant from funding agencies in the public, commercial, or not-for-profit sectors.

\section{References}

1. Dominguez Perez D, AA Rodriguez, H Osorio, J Azevedo, O Castaneda, et al. (2017) Microcystin-LR Detected in a Low Molecular Weight Fraction from a Crude Extract of Zoanthus sociatus. Toxins (Basel) 9(3).

2. Martins MD, MP Russo, JB Lemos, KP Fernandes, SK Bussadori, et al. (2007) Orofacial lesions in treated southeast Brazilian leprosy patients: a cross-sectional study. Oral Dis 13(3): 270-273.

3. Das KK, SN Das, SA Dhundasi (2008) Nickel, its adverse health effects \& oxidative stress. Indian J Med Res 128(4): 412-425.

4. (2016) IARC, IAf Ro Cancer (2016) Agents Classified by the IARC Monographs, France.

5. Rodrigues LC, D Lockwood (2011) Leprosy now: epidemiology, progress, challenges, and research gaps. Lancet Infect Dis United States Elsevier Ltd 11: 464-470.

6. Maurer K, K Eschrich, W Schellenberger, J Bertolini, S Rupf, et al. (2013) Oral brush biopsy analysis by MALDI-ToF Mass Spectrometry for early cancer diagnosis. Oral Oncol 49(2): 152-156.

7. Fresquez MR, RS Pappas, CH Watson (2013) Establishment of toxic metal reference range in tobacco from US cigarettes. J Anal Toxicol 37(5): 298-304.

8. O Connor RJ, LM Schneller, RV Caruso, WE Stephens, Q Li, et al. (2015) Toxic metal and nicotine content of cigarettes sold in China, 2009 and 2012. Tob Control 24(4): 55-59.

9. Khlifi R, P Olmedo, F Gil, B Hammami, A Hamza Chaffai (2015) Cadmium and nickel in blood of Tunisian population and risk of nasosinusal polyposis disease. Environ Sci Pollut Res Int 22(5): 3586-3593. 
10. Gil F, A Pla (2001) Biomarkers as biological indicators of xenobiotic exposure. J Appl Toxicol 21(4): 245-255.

11. Kehrmann J, S Wessel, R Murali, A Hampel, FC Bange, et al. (2016) Principal component analysis of MALDI TOF MS mass spectra separates M. abscessus (sensu stricto) from M. massiliense isolates. BMC Microbiol 16: 24 .

12. Tisch M, G Enderle, J Zoller, H Maier (1996) Cancer of the oral cavity in machine workers. Laryngorhinootologie 75(12): 759-763.

13. Bader M, MC Dietz, A Ihrig, G Triebig (1999) Biomonitoring of manganese in blood, urine and axillary hair following low-dose exposure during the manufacture of dry cell batteries. Int Arch Occup Environ Health 72(8): 521-527.

14. Jensen CS, S Lisby, O Baadsgaard, K Byrialsen, T Menné (2003) Release of nickel ions from stainless steel alloys used in dental braces and their patch test reactivity in nickel-sensitive individuals. Contact Dermatitis 48(6): 300-304.

15. Olmedo P, A Pla, AF Hernandez, O Lopez Guarnido, L Rodrigo, et al. (2010) Validation of a method to quantify chromium, cadmium, manganese, nickel and lead in human whole blood, urine, saliva and hair samples by electrothermal atomic absorption spectrometry. Anal Chim Acta 659(1-2): 60-67.

16. Koseki M, Y Maki, T Matsukubo, Y Ohashi, K Tsubota (2004) Salivary flow and its relationship to oral signs and symptoms in patients with dry eyes. Oral Dis 10(2): 75-80.

17. Navazesh M (1993) Methods for collecting saliva. Ann NY Acad Sci 694: 72-77.

18. Navazesh M, SK Kumar (2008) Measuring salivary flow: challenges and opportunities. J Am Dent Assoc 139 Suppl: 35s-40s.

19. Tisch M, H Maier (1996) Squamous epithelial carcinoma of the tongue after occupational exposure to chromium VI compounds. Laryngorhinootologie 75(8): 455-458.

20. Chiang CT, YH Hwang, C C Su, K Y Tsai, B Lian Ie, et al. (2010) Elucidating the underlying causes of oral cancer through spatial clustering in highrisk areas of Taiwan with a distinct gender ratio of incidence. Geospat Health 4(2): 230-242.

21. Su CC, YY Lin, TK Chang, CT Chiang, JA Chung, et al. (2010) Incidence of oral cancer in relation to nickel and arsenic concentrations in farm soils of patients' residential areas in Taiwan. BMC Public Health 10: 67.

ISSN: 2574-1241

DOI: 10.26717/BJSTR.2018.09.001741

Filipe Ivan Daniel. Biomed J Sci \& Tech Res

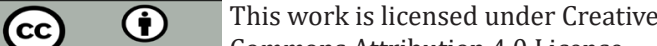

Submission Link: https://biomedres.us/submit-manuscript.php
22. Su CC, KY Tsai, YY Hsu, YY Lin, B Lian Ie (2010) Chronic exposure to heavy metals and risk of oral cancer in Taiwanese males. Oral Oncol 46(8): 586-590.

23. Khlifi R, P Olmedo, F Gil, M Feki Tounsi, B Hammami, et al. (2014) Biomonitoring of cadmium, chromium, nickel and arsenic in general population living near mining and active industrial areas in Southern Tunisia. Environ Monit Assess 186(2): 761-779.

24. Gil F, AF Hernandez, C Marquez, P Femia, P Olmedo, et al. (2011) Biomonitorization of cadmium, chromium, manganese, nickel and lead in whole blood, urine, axillary hair and saliva in an occupationally exposed population. Sci Total Environ 409(6): 1172-1180.

25. Agaoglu G, T Arun, B Izgi, A Yarat (2001) Nickel and chromium levels in the saliva and serum of patients with fixed orthodontic appliances. Angle Orthod 71(5): 375-379.

26. Galo R, RF Ribeiro, RC Rodrigues, L A Rocha, G de Mattos Mda (2012) Effects of chemical composition on the corrosion of dental alloys. Braz Dent J 23(2): 141-148.

27. Reclaru L, RE Unger, CJ Kirkpatrick, C Susz, PY Eschler, et al. (2012) Ni$\mathrm{Cr}$ based dental alloys; Ni release, corrosion and biological evaluation. Mater Sci Eng C Mater Biol Appl 32(6): 1452-1460.

28. Chen B, G Xia, XM Cao, J Wang, BY Xu, et al. (2013) Urinary levels of nickel and chromium associated with dental restoration by nickel-chromium based alloys. Int J Oral Sci 5(1): 44-48.

29. Gutsche P, G Schmalz, M Landthaler (2008) Prevalence of piercing in a German population. Eur J Dermatol 18(1): 26-28.

30. Wataha JC, JL Drury, WO Chung (2013) Nickel alloys in the oral environment. Expert Rev Med Devices 10(4): 519-539.

31. Catalanatto FA, FW Sunderman (1977) Nickel concentrations in human parotid saliva. Ann Clin Lab Sci 7(2): 146-151.

32. Cooke C, S Ahmedzai, J Mayberry (1996) Xerostomia--a review. Palliat Med 10(4): 284-292.

33. Newkirk KA, MD Ringel, L Wartofsky, KD Burman (2000) The role of radioactive iodine in salivary gland dysfunction. Ear Nose Throat J 79(6): 460-468.

34. Afridi HI, FN Talpur, TG Kazi, D Brabazon (2015) Estimation of Aluminum, Arsenic, Lead and Nickel Status in the Samples of Different Cigarettes and their Effect on Human Health of Irish Smoker Hypertensive Consumers. Clin Lab 61(9): 1147-1156.

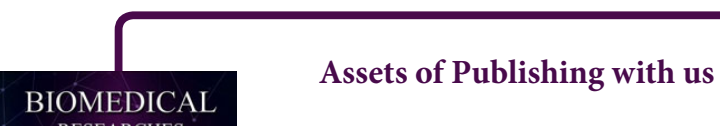

- Global archiving of articles

- Immediate, unrestricted online access

- Rigorous Peer Review Process

- Authors Retain Copyrights

- Unique DOI for all articles

https://biomedres.us/ 